\title{
Technostress from Smartphone Use and Its Impact on University Students' Sleep Quality and Academic Performance
}

\author{
Ni Yao ${ }^{1} \cdot$ Qiong Wang ${ }^{2}$
}

Accepted: 17 February 2022/Published online: 2 March 2022

(C) De La Salle University 2022

\begin{abstract}
Smartphone has been widely used by the younger generation. However, research exploring the technostress triggered by smartphone use lacks. Based upon the stressor-strain-outcome model, this study examined how smartphone use, especially compulsive use, life invasion, and information overload, cause university students' technostress and, furthermore, how technostress impact their sleep quality and academic performance. Data were collected from 540 undergraduates studying at a Chinese public university and analyzed using structural equation modeling. Results revealed that compulsive smartphone use and information overload are both positively associated with technostress, which in turn have a positive effect on poor sleep quality and academic selfperception. Furthermore, compulsive smartphone use indirectly predicts sleep and academic problems through the mediating effect of technostress. The findings contribute to extend the existing technostress literature and provide valuable practical implications for smartphonerelated designers, university teachers, and students.
\end{abstract}

Keywords Technostress - Smartphone use · Information overload · Life invasion . Academic performance . Sleep quality

Ni Yao

xinlitiaoshi@163.com

1 School of Educational Science, Nanjing Normal University of Special Education, No.1 Shennong Road, Qixia District, Nanjing City 210038, Jiangsu Province, China

2 College of Science (Teachers College), Shaoyang University, Shaoyang, China

\section{Introduction}

Smartphone was widely used by university students around the world. On one hand, the benefits of smartphone use are undeniable. It brings students with grateful convenience, such as efficient and quick social interactions, mobile learning, and language learning (Zhang, 2021). On the other hand, overuse of mobile devices may also lead to negative reactions, such as technostress, which refers to individuals' stressful experiences due to the usage of information technologies (Ayyagari et al., 2011; Salo et al., 2019).

Technostress was considered to be negatively associated with individuals' well-being and performance (Brod, 1984; Nimrod \& Galit, 2017; Upadhyaya \& Acharya, 2020). However, the existing research on technostress mainly focused on employees (Tarafdar et al., 2007, 2011), teachers (Dong et al., 2019; Jena, 2015; Li \& Wang, 2020), librarians (Ahmad \& Amin, 2012), and older adults (Nimrod \& Galit, 2017). Only a few researchers concerned the technostress of university students. Although the younger generation is digital natives, researchers have demonstrated that they also experience technostress. For example, Zhao et al. (2021) examined the relationships among university students' technostress, university support, and learning burnout in the context of technologyenhanced learning. They found that university students' technostress is at the upper-middle level. With the wide use of smartphones, the new generation may at a risk of experience increasing technostress. However, the technostress triggered by smartphone use of university students remains scarce.

In this background, this study aims to fulfill the research gaps by employing stressor-strain-outcome (SSO) model to estimate how smartphone use, especially compulsive use, 
life invasion, and information overload, cause university students' technostress, furthermore, how technostress influences their sleep quality and academic performance. Specifically, this study aims to address these two specific issues:

Research question 1: How smartphone compulsive use, life invasion, and information overload influence university students' technostress?

Research question 2: How technostress experienced by university students influences their sleep quality and academic performance?

\section{Literature Review and Hypotheses Development}

\section{Technostress}

Technostress was initially proposed by Brod (1984), who defined it as "a modern disease of adaptation caused by an inability to cope with the new computer technologies in a healthy manner." Then Arnetz and Wiholm (1997) viewed technostress as an arousal state experienced by individuals who need to use computers extensively to complete their work. In recent times, researchers defined it as users' any stress triggered by the usage of information and communications technologies (Ayyagari et al., 2011; Li \& Wang, 2020; Ragu-Nathan et al., 2008), the present study adopt this definition.

The impacts of technostress on individuals may be manifested in physical, psychological, and behavioral aspects. The negative physical reactions include restlessness, headache, and fatigue (Arnetz \& Wiholm, 1997); while the induced psychological effects include burnout, reduced satisfaction with the technology being used, and job (Ayyagari et al., 2011; Maier et al., 2019). Reduced productivity, decreased performance, and innovation are common negative behavioral effects (Ragu-Nathan et al., 2008; Upadhyaya \& Acharya, 2020).

Several researchers have examined the technostress in the context of mobile devices usage. They found that the compulsive use predicts users' technostress positively (Boonjing \& Chanvarasuth, 2017; Hsiao, 2017; Lee et al., 2014). For instance, with a sample of 546 Taiwanese users, Hsiao (2017) confirmed that compulsive use of both mobile social communication and game applications could lead to technostress. However, few studies have explored the specific related stressors that lead to users' technostress when using mobile devices. One exception is Lee et al. (2016). They examined the stressors of mobile communication use in the after-work hours of business workers. They found that social insecurity, life invasion, and work- home conflict are the significant stressors of workers' technostress, which in turn predict their life satisfaction negatively. As far as we known, there is no study examined the antecedents and outcomes of technostress due to smartphone use of university students, who are a special population using smartphones widely. Examination of these associations would provide evidence for a better understanding of students' smartphone usage and intervention.

\section{Research Model}

The stressor-strain-outcome model (SSO) is an influential theoretical paradigm to understand the antecedents and consequences of stress related to technology use. A number of researchers have applied the SSO framework to study stress-related situations (Ayyagari et al., 2011; Dhir et al., 2018; Pang, 2021). The framework includes three main parts, stimulators (stressor), psychological response to stimulators (strain), and physical or mental consequences (outcome). Since SSO framework is completely consistent with the main purposes of the study, we employed it to get a deeper understanding of the determinants and outcomes of university students' technostress resulting from smartphone use.

According to the technostress frame of Tarafdar et al. (2011) and the findings of Hsiao (2017) and Lee et al. (2014), this study identified compulsive smartphone use, information overload, and life invasion as stressors related to smartphone use, while identified the poor sleep quality and academic performance as the related outcomes.

\section{Compulsive Smartphone Use and Technostress}

Compulsive smartphone use was regarded as a problematic use of smartphones, instead of rational use behavior (Panda \& Jain, 2018). It usually manifests itself in the following characteristics: (1) unable to control the impulse to use smartphones; (2) falling into distressed when smartphones are inaccessible; (3) feeling excited when using smartphones even when one is fatigue; and (4) feeling restless when stop using smartphones.

Smartphones' characteristics of powerful engagement, such as computing function, entertainment capabilities, and constant Internet connectivity, may lead to users' uncontrolled use urge (Panda \& Jain, 2018). On average, users touch their smartphones more than 2000 times per day (Dscout, 2016). In the recent times, people are using mobile phones more extensively due to the lockdown during the COVID-19 break (Sebire, 2020). Student is a 
population at a higher risk, up to $61 \%$ of parents considered their children as smart devices addict (Robb, 2019). In China, up to $31.5 \%$ of college students have the problem of excessive mobile phone use (Fu \& Peng, 2020).

In recent years, because of the wide popularity and disturbing consequences, compulsive smartphone use has attracted researchers' increasing attention (Panda \& Jain, 2018; Wang et al., 2014). Researchers have confirmed that smartphones compulsive use would bring negative effects on users (Panda \& Jain, 2018; Samaha \& Hawi, 2016; Wang et al., 2015). In addition, several researchers found that compulsive use of mobile phones probably leads to technostress (Boonjing \& Chanvarasuth, 2017; Panda \& Jain, 2018). In this regard, this study formulated the hypothesis that university students' compulsive smartphone use is positively associated with their technostress (H1).

\section{Life Invasion and Technostress}

Previous researchers have studied life invasion in different contexts of technology usage. In organizational context, life invasion describes the situations where employee' personal life is being invaded by work related matters due to the extensive connectivity of ICT (Gaudioso et al., 2017; Ragu-Nathan et al., 2008). In this context, employee may have to handle work issues at after-work hours. As a result, the boundaries between work and family may blur. In the nonorganizational context, life invasion refers to users' perception of their daily life being invaded due to the excessive centrality of the diverse ICT tools being used, such as social networks sites (Cao \& Sun, 2018; Maier et al., 2015). As a result, the time and efforts spent on other worthwhile things would be reduced.

In this study, life invasion refers to university students' negative perception that smartphone plays a too central role and has invaded their personal life. Students may experience life invasion due to the ubiquitous Internet connectivity and various applications of smartphone use. For instance, WeChat, a widely used social software in China, which has been installed on almost every university student's smartphone and enables them to be online $24 \mathrm{~h}$ a day. Students may continuously check their WeChat with smartphones when dealing with other worthwhile activities that need to be focused, such as learning, attending meetings, playing sports, and face-to-face conversation.

In the technostress literature, life invasion was considered to be positively associated with technostress (RaguNathan et al., 2008; Tarafdar et al., 2007). Similarly, Xiao and Mou (2019) also confirmed that life invasion due to Wechat use leads to users' social media fatigue. Therefore, this study formulated the hypothesis that life invasion due to smartphone use is positively associated with university students' technostress (H2).

\section{Information Overload and Technostress}

Users can obtain a huge amount of information quickly and conveniently using smartphone. However, information overload, which refers to the situation in which individuals are exposed to more information than they can effectively handle, has become a pervasive issue (Fu et al., 2020). Information overload is identified as a key factor leading to the negative consequences of digital technology use (Lee et al., 2016).

In this study, information overload describes the situation where students are exposed to excessive information via smartphone, which beyond their capability to process. The smartphone may increase the risk of information overload at least in these two aspects. First, universities tend to release information about learning and management through social class groups, such as WeChat group. However, these social groups are often filled with a lot of irrelevant information such as chatting, advertising, and rumors. Second, other diverse apps on smartphones usually push messages and notifications to students constantly and automatically. Since students' cognitive ability is limited, they may not be able to handle the constant flow of information through their smartphones effectively.

Previous studies have confirmed that different types of overload, inclusive of information overload, could lead to users' social media exhaustion, and then consequently, result in the discontinuous usage of social media (Fu et al., 2020). Tarafdar et al. (2007) and Ragu-Nathan et al. (2008) also proposed that continuous information overload will lead to technostress. Similarly, Arla et al. (2012) identified information overload as a formative indicator of technostress. Hence, we formulated the hypothesis that information overload due to smartphone use is positively associated with students' technostress (H3).

\section{Technostress and Sleep Quality}

It is found that up to $60 \%$ university students suffer from sleep difficulties, such as decreased sleep duration and difficult in falling asleep (Foulkes et al., 2019). Poor sleep quality may lead to diverse and serious consequences, such as physical ill-being, mental problems, and mortality (Freeman et al., 2017). For students, another common negative outcome of insufficient sleep is poor academic performance. Researchers have confirmed that sleep quality is negatively associated with students' academic achievements (Gomes et al., 2011). University students with longer sleep duration are more likely to get higher grade point averages (Kelly et al., 2001).

Researchers studied that the negative effects of smartphone use have proved that the overuse of smartphone is positively associated with individuals' poor quality of sleep 
(The Guardian, 2017). Since stress is an important contributor to individuals' sleep problems (Greubel \& Kecklund, 2011; Lazarus \& Folkman, 1984), excepting that smartphone use would take up some sleep time, resulting in insufficient sleep (Salo et al., 2019), another possible explanation is the technostress resulting from smartphone use leads to users' sleep difficulties or challenges. Therefore, we formulated the hypothesis that technostress is positively associated with university students' poor sleep quality (H4).

\section{Technostress and Academic Performance}

Some prior studies have examined the impact of technostress on students' academic performance. For instance, Cao and Sun (2018) examined the association between students' academic performance and their usage of mobile social-networking sites. They found that the strain triggered by the overuse of mobile social-networking sites predicts students' poor academic significantly. Similarly, Upadhyaya and Acharya (2020) also confirmed that technostress is negatively associated with university students' academic productivity. However, Qi (2019) investigated the effect of technostress in the context of university students' mobile devices usage for academic purposes. The findings indicated that technostress has no significant effect on academic performance. Therefore, the existing findings about the influence of technostress on students' academic performance are inconsistent. In the recent times, smartphones are being extensively used by the university students as valuable learning, communication, and entertainment tools (Zhang, 2021). Therefore, it is necessary to understand how technostress impacts the academic performance of this population.

In this study, we measured students' academic selfperception, which refers to the extent to which students are confident in their abilities to succeed in school and to evaluate students' academic performance. We temporarily proposed that technostress is positively associated with students' poor academic self-perception (H5).

\section{Method}

\section{Participants}

For Chinese university students, smartphones are available to everyone and have been widely used for various purposes. Thus, we adopted a convenient sampling method and selected a public university in southern China for data collection. Data collection lasted for two weeks (May 15 to
May 29, 2021). Since the senior students were practicing or looking for jobs during this period, they were not included in our study. The research team sent the online questionnaire via WeChat to about 600 potential respondents in various majors, including science of law, English, political economy, mechanical automation, and electrical automation, and invited them to participate anonymously and voluntarily. A total of 549 responses were received, of which nine incomplete responses were excluded. Therefore, the valid data for empirical analysis were 540 . The demographic information of the respondents is summarized in Table 1.

\section{Measurements}

The questionnaire used in this study included two parts. First, items were designed to collect the respondents' demographic information. Second, a scale was developed to test the six constructs of this study. All the 19 items in this part were presented in form of Five-point Likert scale and were adopted from relevant literature with ideal reliability and validity.

Specifically, the subscale of compulsive smartphone use was revised from Panda \& Jain (2018) to test the extent to which university students use smartphone frequently and unable to control the eager to use. The subscale of life invasion was adopted from the study of $\mathrm{Cao}$ and Sun (2018). The information overload subscale was revised from $\mathrm{Fu}$ et al. (2020) to test the extent to which students feel overwhelmed by the amount of information exposed to them through smartphone. The poor sleep quality subscale was revised from Panda \& Jain (2018). The poor academic self-perception subscale was adopted from Hsiao et al. (2017). Items were inversely encoded ranging from 1 (totally agree) to 5 (totally disagree).

A preliminary test was conducted with 10 university students after the completion of the questionnaire development. According to their feedback, language expression was adjusted to eliminate possible ambiguity and misunderstanding.

\section{Data Analysis}

SPSS 20.0 and AMOS 24.0 were used for data analysis. First, to test the measurement model, we performed confirmatory factor analysis and calculated the Cronbach's alpha coefficients. Second, structural equation modeling was conducted to verify the research model and test the research hypotheses. Last, the mediating effect of technostress was calculated. 
Table 1 The demographic information of participants

\begin{tabular}{|c|c|c|c|c|c|}
\hline & Number & Percentage & Age & Number & Percentage \\
\hline \multicolumn{6}{|l|}{ Gender } \\
\hline Female & 161 & 29.81 & $<18$ & 29 & 5.37 \\
\hline Male & 379 & 70.19 & $18-20$ & 510 & 94.44 \\
\hline Smartphone use per day & & & $>20$ & 1 & 0.19 \\
\hline$<3 \mathrm{~h}$ & 50 & 9.26 & Grade & & \\
\hline $3-5 \mathrm{~h}$ & 185 & 34.26 & Freshman & 246 & 45.56 \\
\hline $6-8 \mathrm{~h}$ & 217 & 40.19 & Sophomore & 262 & 48.52 \\
\hline$>8 \mathrm{~h}$ & 88 & 16.30 & Junior & 32 & 5.93 \\
\hline
\end{tabular}

\section{Results}

\section{Descriptive Statistics}

The means of the six latent variables are shown in Table 2 . The results suggested that the students' compulsive use behaviors and their perception of life invasion, technostress, poor sleep quality, and academic self-perception are at relatively low levels with means less than 3 , while their perception of information overload is relatively high $($ mean $=3.15)$.

\section{The Measurement Model}

The measurement model was examined with the following indicators: item and construct reliability, convergent validity, discriminant validity, and the fitness of the measurement model.

Calculation results (shown in Table 2) revealed that the standardized factor loadings of the 19 items are all above 0.50 (ranging from 0.524 to 0.941 ). In addition, the Cronbach's alpha coefficients of the six latent variables are all above 0.80 (ranging from 0.826 to 0.927 ). All these values meet the criteria recommended by Schumacker and Lomax (2004), suggesting a satisfactory item reliability and construct reliability.

The convergent validity was examined by composite reliability (CR) and average variance extracted (AVE). Fornell and Larcker (1981) recommended that the coefficients of CR should not be lower than 0.70, while AVE should not be lower than 0.50. In this study, the calculation results revealed that the six constructs' CR coefficients

Table 2 Results of construct validity and reliability analysis

\begin{tabular}{|c|c|c|c|c|c|c|c|}
\hline Construct & Item & Loading & $\alpha$ & CR & AVE & Mean & SD \\
\hline \multirow[t]{3}{*}{ Compulsive smartphone use } & CSU1 & 0.927 & \multirow[t]{3}{*}{0.922} & \multirow[t]{3}{*}{0.927} & \multirow[t]{3}{*}{0.809} & \multirow[t]{3}{*}{2.93} & \multirow[t]{3}{*}{0.87} \\
\hline & CSU2 & 0.922 & & & & & \\
\hline & CSU3 & 0.847 & & & & & \\
\hline \multirow[t]{3}{*}{ Life invasion } & LI1 & 0.941 & \multirow[t]{3}{*}{0.900} & \multirow[t]{3}{*}{0.931} & \multirow[t]{3}{*}{0.818} & \multirow[t]{3}{*}{2.38} & \multirow[t]{3}{*}{0.83} \\
\hline & $\mathrm{LI} 2$ & 0.849 & & & & & \\
\hline & LI3 & 0.921 & & & & & \\
\hline \multirow[t]{3}{*}{ Information overload } & IO1 & 0.768 & \multirow[t]{3}{*}{0.865} & \multirow[t]{3}{*}{0.868} & \multirow[t]{3}{*}{0.687} & \multirow[t]{3}{*}{3.15} & \multirow[t]{3}{*}{0.84} \\
\hline & $\mathrm{IO} 2$ & 0.892 & & & & & \\
\hline & IO3 & 0.822 & & & & & \\
\hline \multirow[t]{4}{*}{ Technostress } & TS1 & 0.845 & \multirow[t]{4}{*}{0.826} & \multirow[t]{4}{*}{0.837} & \multirow[t]{4}{*}{0.569} & \multirow[t]{4}{*}{2.14} & \multirow[t]{4}{*}{0.89} \\
\hline & TS2 & 0.798 & & & & & \\
\hline & TS3 & 0.806 & & & & & \\
\hline & TS4 & 0.524 & & & & & \\
\hline \multirow[t]{3}{*}{ Poor sleep quality } & PSQ1 & 0.841 & \multirow[t]{3}{*}{0.927} & \multirow[t]{3}{*}{0.929} & \multirow[t]{3}{*}{0.814} & \multirow[t]{3}{*}{2.66} & \multirow[t]{3}{*}{0.87} \\
\hline & PSQ2 & 0.932 & & & & & \\
\hline & PSQ3 & 0.931 & & & & & \\
\hline \multirow[t]{3}{*}{ Poor academic self-perception } & PAS1 & 0.821 & \multirow[t]{3}{*}{0.881} & \multirow[t]{3}{*}{0.882} & \multirow[t]{3}{*}{0.715} & \multirow[t]{3}{*}{2.21} & 0.81 \\
\hline & PAS2 & 0.93 & & & & & \\
\hline & PAS3 & 0.778 & & & & & \\
\hline
\end{tabular}


Fig. 1 The research model. This model was adopted from Ayyagari et al. (2011)and adjusted according to the characteristics of smartphone use of university students

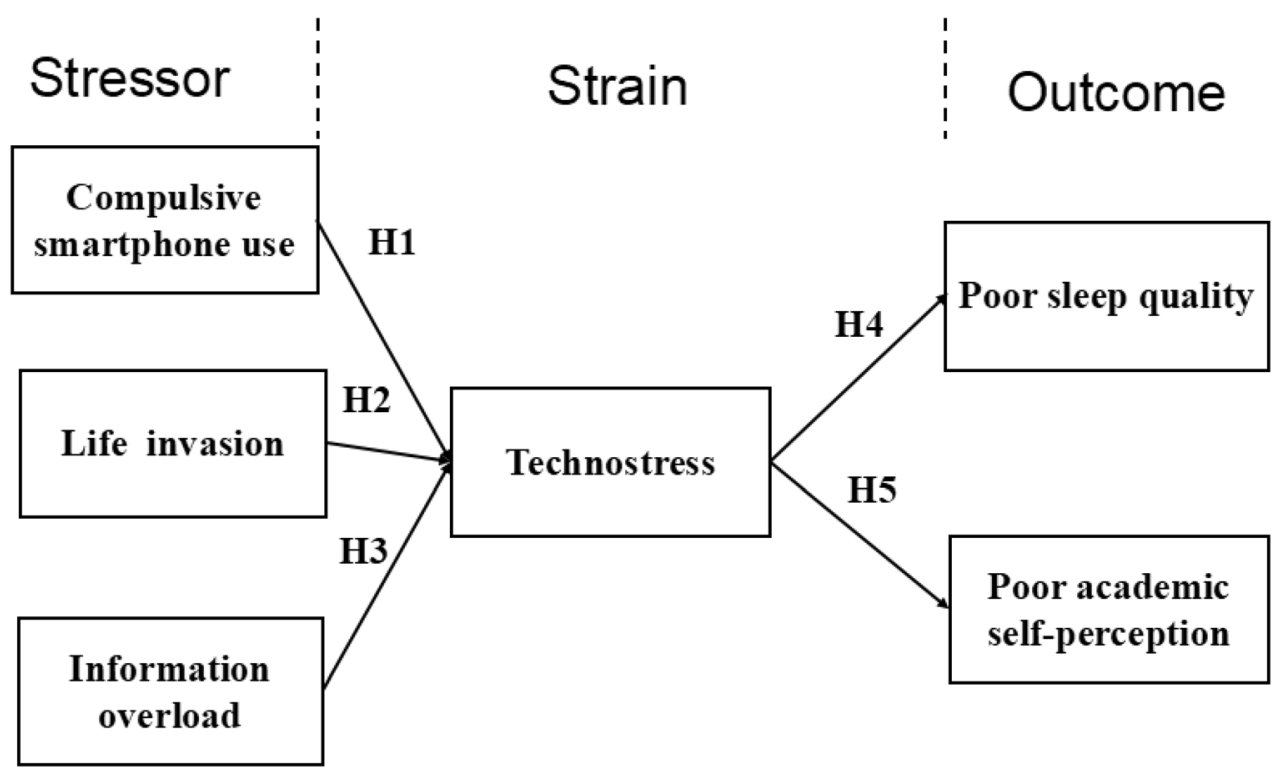

Table 3 Discriminate validity

\begin{tabular}{llllll}
\hline Constructs & 1 & 2 & 3 & 4 & 5 \\
\hline CSU & 0.899 & & & & \\
LI & 0.561 & 0.904 & 0.829 & & \\
IO & 0.029 & 0.010 & 0.072 & 0.754 & 0.902 \\
TS & 0.175 & 0.136 & 0.180 & 0.404 & 0.602 \\
PSQ & 0.077 & 0.050 & 0.206 & 0.326 & 0.846 \\
PAS & 0.012 & 0.010 & & & \\
\hline
\end{tabular}

$C S U$ compulsive smartphone use, $L I$ Life invasion, $I O$ information overload, $T S$ technostress, $P S Q$ poor sleep quality, $P A S$ poor academic selfperception

were all above 0.80 , ranging from 0.882 to 0.931 ; AVE coefficients were between 0.569 and 0.818 . Therefore, the convergent validity of this study is acceptable (Fig. 1).

Furthermore, the AVE coefficient of each latent variable is higher than the correlation coefficients between that and other latent variables (Table 3), suggesting an acceptable discriminant validity (Chin, 1998).

As for the fitness of the measurement model, the values of the key indicators $\left(\chi^{2} / \mathrm{df}=2.807\right.$, GFI $=0.931$, TLI $=$ $0.959, \mathrm{CFI}=0.968, \mathrm{RMR}=0.068, \mathrm{RMSEA}=0.058)$ all meet the criteria proposed by $\mathrm{Hu}$ and Bentler (1999).

\section{The Hypotheses Testing}

The results of hypotheses testing revealed that compulsive smartphone use $(\beta=0.178, P<0.05)$ and information overload $(\beta=0.180, P<0.05)$ are both positively associated with technostress, supporting $\mathrm{H} 1$ and $\mathrm{H} 2$. However, the association between life invasion and technostress in not significant $(\beta=0.011, P>0.05)$, rejecting H3. In addition, the squared multiple correlation coefficient of technostress was 0.252 , suggesting that compulsive use, life invasion, and information overload have a certain explanatory power to technostress. Technostress is positively associated with both poor sleep quality $(\beta=0.450$, $P<0.001)$ and poor academic self-perception $(\beta=0.348$, $P<0.001$ ), supporting $\mathrm{H} 4$ and H5. Figure 2 shows the results of hypotheses testing with standardized coefficients. In addition, we also tested whether technostress mediates the relationships between compulsive smartphone use, information overload, and the consequences. The calculation results indicated that the impacts of compulsive smartphone use on both poor sleep quality and academic self-perception are not significant when technostress is added. However, technostress-mediating effect in the association between information overload and consequences is not significant. These calculation results confirmed that technostress plays a mediating role in the influence of compulsive smartphone use on students' poor sleep quality and academic self-perception (Table 4). 
Fig. 2 The research model with its standardized coefficients

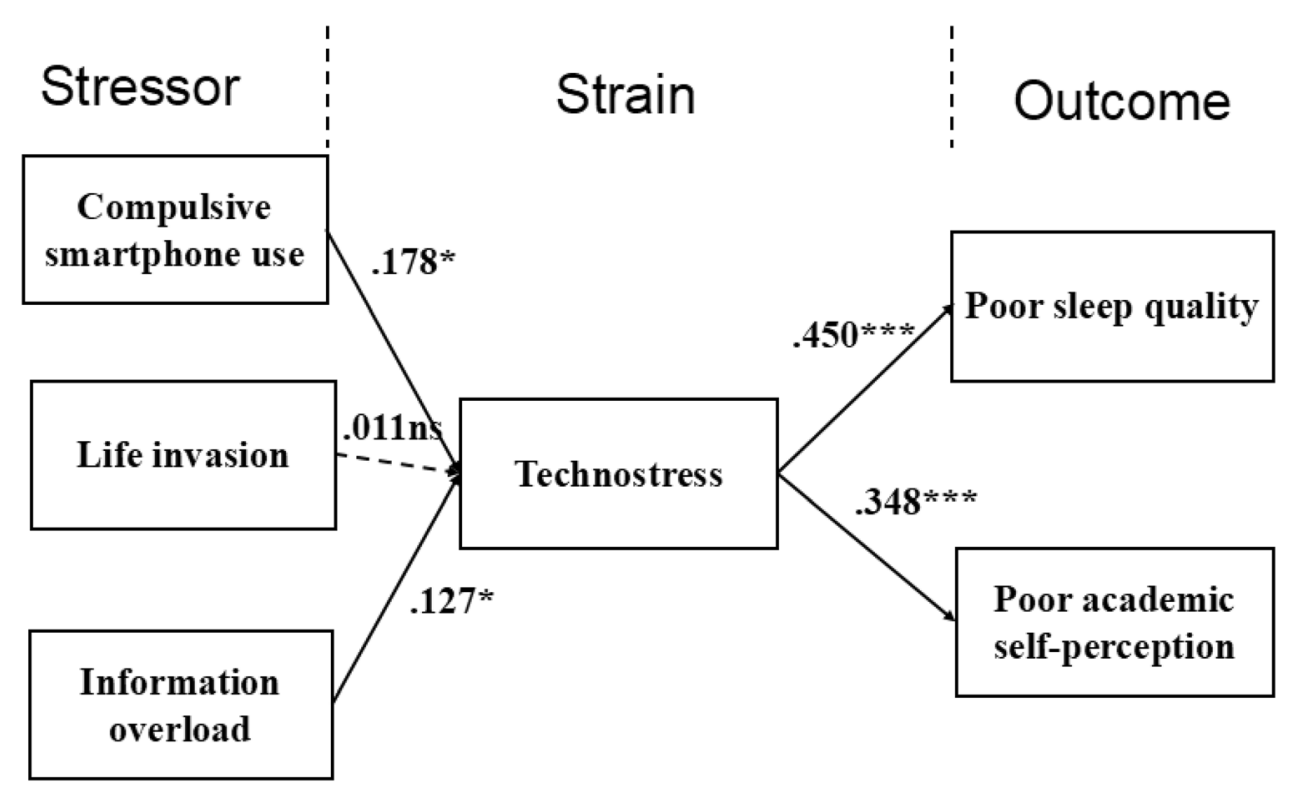

Table 4 The results of hypotheses testing

\begin{tabular}{lllllll}
\hline Hypotheses & Hypothesized path & $B$ & $\beta$ & S.E & $t$ & Supported? \\
\hline H1 & CSU $\rightarrow$ TS & 0.221 & 0.178 & 0.102 & $2.168^{*}$ & Yes \\
H2 & LI $\rightarrow$ TS & 0.015 & 0.011 & 0.107 & 0.137 & No \\
H3 & IO $\rightarrow$ TS & 0.180 & 0.127 & 0.069 & $2.607^{*}$ & Yes \\
H4 & TS $\rightarrow$ PSQ & 0.376 & 0.450 & 0.040 & $9.509^{* * *}$ & Yes \\
H5 & TS $\rightarrow$ PAS & 0.328 & 0.348 & 0.046 & $7.145^{* * *}$ & Yes \\
\hline
\end{tabular}

$C S U$ compulsive smartphone use, $L I$ Life invasion, $I O$ information overload, $T S$ technostress, $P S Q$ poor sleep quality, $P A S$ poor academic selfperception

$* * * P<0.001, * * P<0.01, * P<0.05$

\section{Discussion}

Building upon the existing literature of technostress and SSO model, this study aims to unfold the mechanism of the influences of compulsive smartphone use, life invasion, and information overload on university students' life. Specifically, this study employed a theoretical model and highlighted the mediating role of technostress in the relationship between students' smartphone use and their poor sleep quality and academic performance. The empirical results indicated that the research model has valuable explanatory power to understand university students' technostress.

\section{The Antecedents of Technostress When Using Smartphone}

The results indicated that compulsive smartphone use is positively associated with students' technostress. Maier et al. (2015) also confirmed that SNS overuse would lead to pressure. Similarly, both Lee et al. (2014) and Hsiao et al.
(2017) demonstrated that compulsive mobile phone apps use has a positive impact on technostress. The compulsive users may be eager to use their smartphones frequently, regardless of the time, space, and the matters at hand (Lapointe et al., 2013), which may result in their pressure.

As for the information overload, the result indicated that it is also positively associated with students' technostress. This finding is in line with previous studies which confirmed that information overload would lead to negative impacts on users (Fu et al., 2020; Lee et al., 2016). Our finding furthers the previous research by examining the influence of information overload in the context of students' smartphone use. The endless stream of information from smartphone probably exceeds the student's ability to handle it effectively.

Different from the research hypothesis, the results indicated that life invasion has no significant association with technostress. This finding is inconsistent with prior studies (Tarafdar et al., 2007; Xiao \& Mou, 2019). We provide two possible explanations for this finding. First, previous researchers such as Xiao and Mou (2019) and 
Tarafdar et al. (2007) mainly concerned the ICT use demanded by job, users may have to process work-related information or even handle work issues because the connectivity of ICT at after-work hours, consequently, the boundary between work and family may be blurred and their perceptions of technostress may be increased. However, to college students, smartphone use is usually not because of the requirements of work or learning, but their own choice. Second, participants of the two aforementioned studies are adults over 26 years old, while the respondents of this study are students under the age of 20 . The younger generation is more accustomed to communicating with mobile phones and Internet (Cao \& Sun, 2018), life invasion may not trigger their perception of technostress.

\section{The Effects of Technostress}

The results indicated that technostress is positively associated with university students' poor sleep quality. This finding is in line with the previous studies which confirmed the negative influences of technostress (Ragu-Nathan et al., 2008; Zhao et al., 2021). Since excessive technostress is likely to trigger individuals' negative physical and psychological reactions (Arnetz \& Wiholm, 1997; Ayyagari et al., 2011), this study further confirms that technostress may also lead to sleep problems.

The results also indicated that technostress probably leads to students' poor academic self-perception. This finding is in line with Upadhyaya and Acharya (2020), which argued significant negative association between technostress and academic performance; while is inconsistent with Hsiao et al. (2017) and Qi (2019) which confirmed no significant effect. The inconsistent conclusions may result from the different methods used to measure participants' academic achievement and the characteristics of participants themselves.

In addition, according to the mediation analysis, technostress may exert a mediating effect on the associations between compulsive smartphone use and negative outcomes (i.e., poor sleep quality and academic self-perception). These findings again strengthen the mediating effect of psychological strain between stressors and adverse outcomes (Pang, 2021; Whelan et al., 2020).

\section{Implications}

Theoretically, this study contributes to extend the current technostress literature by investigating technostress of university students. Although the previous researchers have realized that the younger generation may at a risk of experience increasing technostress (Upadhyaya \& Acharya, 2020), the associations between compulsive smartphone use, life invasion, information overload, technostress, and negative influences remain unclear. The present research is probably the initial study to empirically investigate these associations of this special population. Second, this research confirms the mediating effect of technostress in the influence of compulsive smartphone use on sleep quality and academic performance. Although existing studies have found that smartphone overuse would lead to adverse impacts on well-being and academic performance (Hsiao et al., 2017; Panda \& Jain, 2018; Pang, 2021), the underlying mechanisms have not been fully investigated. Third, although previous researchers have studied university students' well-being and academic performance from various aspects, such as remote learning, university life, social support, and voice behavior (Foulkes et al., 2019; Horita et al., 2020), few studies have concerned the influence of technostress due to smartphone use. This study developed a research model unpacking how three types of stressors related to smartphone use influence sleep and academic performance of university students, which provide a new research perspective to understand the life of this population.

The findings also provide some practical implications for technostress researchers, smartphone-related designers, university teachers, and students. First, the research model of this study may provide a guide for further researchers to investigate diverse dimensions of technostress by employing additional exploratory variables. Second, the predictive effect of compulsive smartphone use and information overload on technostress suggests that control these two stressors can mitigate students' technostress. Therefore, prevention mechanisms against the students' eagerness of compulsive smartphone use need to be explored. It may be advisable for students to develop a variety of interests and hobbies after enrolled to university, such as joining student clubs and making new friends. Teachers can require students to keep smartphones out of reach or turn them off during class. Physical activity also can reduce smartphone overuse significantly (Abbasi et al., 2021). In addition, practical measures should be taken to minimize information overload to allow students concentrate and pay attention to the things they are doing. Smartphone app providers should take measures to reduce information overload at its source, such as using infographics instead of text. Given the negative effects of technostress, stress coping training, which instructs students to adopt appropriate strategies to cope with technostress, is necessary.

\section{Limitations and Further Research}

This research has certain limitations. First, this study only examined the technostress of smartphone use in the general sense. However, university students usually use smartphones 
for various purposes, such as entertainment, communication, learning, and games. Since the experiences of using smartphones may vary with different purposes, further research may explore the technostress of mobile phone use for specific purpose. Second, data of this study was collected from online survey with nonrandom sampling, and the sample size is relatively small. Future researchers could replicate this study with more systematic sampling methods and larger samples.

\section{Conclusion}

Employing the paradigm of SSO, this study examined the antecedents and consequences of university students' technostress when using smartphone. This study may be the first to concern the technostress of university students from the perspective of smartphone use. The findings provide evidences that technostress associated with smartphone use could lead to technostress, which in turn impacts students' sleep and academic performance. Hence, it is necessary for universities to guide students use smartphone rationally.

Acknowledgements This study was partially funded by the Hunan Social Science Achievement Evaluation Committee (Project Number: XSP22YBC437 and XSP22YBZ009). The authors would like to thank all the university students who participated in the study.

\section{References}

Abbasi, G. A., Jagaveeran, M., Goh, Y.-N., \& Tariq, B. (2021). The impact of type of content use on smartphone addiction and life invasion: Physical activity as moderator. Technology in Society, 64(C). https:// ideas.repec.org/a/eee/teinso/v64y2021ics0160791x20313245.html

Ahmad, U. N. U., \& Amin, S. M. (2012). The dimensions of technostress among Academic Librarians. Procedia - Social and Behavioral Sciences, 65, 266-271. https://doi.org/10.1016/j. sbspro.2012.11.121

Arla, D., Stephanie, P., Natasha, S., \& Laura, H. (2012). Perceived information and communication technology (ict) demands on employee outcomes: The moderating effect of organizational ICT support. Journal of Occupational Health Psychology, 4(17), 473-491. https://doi.org/10.1037/a0029837

Arnetz, B. B., \& Wiholm, C. (1997). Technological stress: Psychophysiological symptoms in modern offices. Journal of Psychosomatic Research, 43(1), 35-42. https://doi.org/10.1016/ S0022-3999(97)00083-4

Ayyagari, R., Grover, V., \& Purvis, R. (2011). Technostress: Technological antecedents and implications. MIS Quarterly, 35(4), 831-858. https://doi.org/10.2307/41409963

Boonjing, V., \& Chanvarasuth, P. (2017). Risk of overusing mobile phones: Technostress effect. Procedia Computer Science, 111, 196-202. https://doi.org/10.1016/j.procs.2017.06.053

Brod, C. (1984). Technostress: The human cost of the computer revolution. Addison Wesley Publishing Company.

Cao, X., \& Sun, J. (2018). Exploring the effect of overload on the discontinuous intention of social media users: An S-O-R perspective. Computers in Human Behavior, 81, 10-18. https://doi.org/10.1016/j.chb.2017.11.035

Chin, W. W. (1998). Issues and opinion on structural equation modeling. MIS Quarterly, 22(1), 7-41. https://doi.org/10.2307/ 249676

Davies, G. (2015). Online MCQ assessment anxiety amongst first year undergraduate psychology students: A case study. Journal of Perspectives in Applied Academic Practice, 3(1), 84-89. https://doi.org/10.14297/jpaap.v3i1.143

Dhir, A., Yossatorn, Y., Kaur, P., \& Chen, S. (2018). Online social media fatigue and psychological wellbeing. A study of compulsive use, fear of missing out, fatigue, anxiety and depression. International Journal of Information Management The Journal for Information Professionals, 40, 141-152. https://doi.org/ 10.1016/j.ijinfomgt.2018.01.012

Dong, Y., Xu, C., Chai, C. S., \& Zhai, X. (2019). Exploring the structural relationship among teachers' technostress, technological pedagogical content knowledge (TPACK), computer selfefficacy and school support. The Asia-Pacific Education Researcher, 29(2), 147-157. https://doi.org/10.1007/s40299019-00461-5

Dscout (2016) Mobile touches report. Retrieved 3rd November 2017. https://blog.dscout.com/hubfs/downloads/dscout_mobile_ touches_study_2016.pdf

Fornell, C., \& Larcker, D. F. (1981). Structural equation models with unobservable variables and measurement error: Algebra and statistics. SAGE Publications.

Foulkes, L. E., Mcmillan, D., \& Gregory, A. (2019). A bad night's sleep on campus: An interview study of first year university students with poor sleep quality. Sleep Health. https://doi.org/ 10.1016/j.sleh.2019.01.003

Freeman, D., Sheaves, B., Goodwin, G., \& M. et al,. (2017). The effects of improving sleep on mental health (OASIS): A randomised controlled trial with mediation analysis. The Lancet Psychiatry, 4(10), 749-758. https://doi.org/10.1016/S2215-0366 (17)30328-0

Fu, B., \& Peng, B. (2020). The relationship between problematic mobile phone use, shyness and loneliness among college students in Jiangxi Province. Chinese Journal of School Health, $41,125-127$.

Fu, S., Li, H., Liu, Y., Pirkkalainen, H., \& Salo, M. (2020). Social media overload, exhaustion, and use discontinuance: Examining the effects of information overload, system feature overload, and social overload. Information Processing \& Management, 57(6), 102307. https://doi.org/10.1016/j.ipm.2020.102307

Gaudioso, F., Turel, O., \& Galimberti, C. (2017). The mediating roles of strain facets and coping strategies in translating techno-stressors into adverse job outcomes. Computers in Human Behavior, 69, 189-196. https://doi.org/10.1016/j.chb.2016.12.041

Gomes, A. A., Tavares, J., \& de Azevedo, M. H. P. (2011). Sleep and academic performance in undergraduates: A multi-measure, multi-predictor approach. Chronobiology International, 28(9), 786-801. https://doi.org/10.3109/07420528.2011.606518

Greubel, J., \& Kecklund, G. (2011). The impact of organizational changes on work stress, sleep, recovery and health. Industrial Health, 49, 353-364. https://doi.org/10.2486/indhealth.MS1211

Horita, R., Nishio, A., \& Yamamoto, M. (2020). The effect of remote learning on the mental health of first year university students in Japan. Psychiatry Research, 295, 113561. https://doi.org/10. 1016/j.psychres.2020.113561

Hsiao, K.-L. (2017). Compulsive mobile application usage and technostress: The role of personality traits. Online Information Review, 41, 272-295. https://doi.org/10.1108/OIR-03-2016-0091

Hsiao, K.-L., Shu, Y., \& Huang, T.-C. (2017). Exploring the effect of compulsive social app usage on technostress and academic performance: Perspectives from personality traits. Telematics 
and Informatics, 34(2), 679-690. https://doi.org/10.1016/ j.tele.2016.11.001

Hu, L., \& Bentler, P. M. (1999). Cutoff criteria for fit indexes in covariance structure analysis: Conventional criteria versus new alternatives. Structural Equation Modeling: A Multidisciplinary Journal, 6(1), 1-55. https://doi.org/10.1080/10705519909540118

Jena, R. K. (2015). Technostress in ICT enabled collaborative learning environment: An empirical study among Indian academician. Computers in Human Behavior, 51, 1116-1123. https://doi.org/10.1016/j.chb.2015.03.020

Kelly, W., Kelly, K. E., \& Clanton, R. C. (2001). The relationship between sleep length and grade-point average among college students. College Student Journal, 35, 84-86.

Lapointe, L., Boudreau-Pinsonneault, C., \& Vaghefi, I. (2013). Is smartphone usage truly smart? A qualitative investigation of IT addictive behaviors. Proceedings of the Annual Hawaii International Conference on System Sciences. https://doi.org/10.1109/ HICSS.2013.367

Lazarus, R. S., \& Folkman, S. (1984). Stress, appraisal, and coping. Springer Publishing Company.

Lee, A. R., Son, S.-M., \& Kim, K. (2016a). Information and communication technology overload and social networking service fatigue: A stress perspective. Computers in Human Behavior, 55, 51-61. https://doi.org/10.1016/j.chb.2015.08.011

Lee, S., Lee, S. C., \& Suh, Y. (2016b). Technostress from mobile communication and its impact on quality of life and productivity. Total Quality Management \& Business Excellence, 27, 1-16. https://doi.org/10.1080/14783363.2016.1187998

Lee, Y.-K., Chang, C.-T., Lin, Y., \& Cheng, Z.-H. (2014). The dark side of smartphone usage: Psychological traits, compulsive behavior and technostress. Computers in Human Behavior, 31, 373-383. https://doi.org/10.1016/j.chb.2013.10.047

Li, L., \& Wang, X. (2020). Technostress inhibitors and creators and their impacts on university teachers' work performance in higher education. Cognition, Technology \& Work, 23(2), 315-330. https://doi.org/10.1007/s10111-020-00625-0

Maier, C., Laumer, S., Weinert, C., \& Weitzel, T. (2015). The effects of technostress and switching stress on discontinued use of social networking services: A study of Facebook use. Information Systems Journal, 25(3), 275-308. https://doi.org/10.1111/isj.12068

Maier, C., Laumer, S., Wirth, J., \& Weitzel, T. (2019). Technostress and the hierarchical levels of personality: A two-wave study with multiple data samples. European Journal of Information Systems, 28(5), 496-522. https://doi.org/10.1080/0960085X.2019. 1614739

Nimrod \& Galit. (2017). Technostress: Measuring a new threat to well-being in later life. Aging \& Mental Health. https://doi.org/ 10.1080/13607863.2017.1334037

Panda, A., \& Jain, N. (2018). Compulsive smartphone usage and users' Ill-being among young Indians: Does personality matter? Telematics and Informatics. https://doi.org/10.1016/j.tele.2018. 03.006

Pang, H. (2021). How compulsive WeChat use and information overload affect social media fatigue and well-being during the COVID-19 pandemic? A stressor-strain-outcome perspective. Telematics and Informatics. http://www.sciencedirect.com/ science/article/pii/S0736585321001295

Qi, C. (2019). A double-edged sword? Exploring the impact of students' academic usage of mobile devices on technostress and academic performance. Behaviour \& Information Technology, 38(12), 1337-1354. https://doi.org/10.1080/0144929X.2019.1585476

Ragu-Nathan, T. S., Tarafdar, M., Ragu-Nathan, B. S., \& Tu, Q. (2008). The consequences of technostress for end users in organizations: Conceptual development and empirical validation. Information Systems Research, 19(4), 417-433. https://doi.org/10.1287/isre.1070.0165
Robb, M. (2019). The new normal: Parents, teens, screens, and sleep in the United States. Common Sense Media. Retrieved November 5, 2020 from https://www.commonsensemedia.org/videos/ the-new-normal-parents-teens-screens-and-sleep-in-the-unitedstates

Salo, M., Pirkkalainen, H., \& Koskelainen, T. (2019). Technostress and social networking services: Explaining users' concentration, sleep, identity, and social relation problems. Information Systems Journal, 29(2), 408-435. https://doi.org/10.1111/isj.12213

Samaha, M., \& Hawi, N. S. (2016). Relationships among smartphone addiction, stress, academic performance, and satisfaction with life. Computers in Human Behavior. https://doi.org/10.1016/j. chb.2015.12.045

Schumacker, R. E., \& Lomax, R. G. (2004). A beginner's guide to structural equation modeling. Psychology Press.

Sebire, K. The coronavirus lockdown is forcing us to view 'screen time' differently. That's a good thing. The Conversation; 2020. Retrieved November 5, 2020 from https://www.theconversation com/the-coronavirus-lockdown-is-forcing-us-to-view-screen-timedifferentlythats-a-good-thing-135641

Tarafdar, M., Tu, Q., Ragu-Nathan, B. S., \& Ragu-Nathan, T. S. (2007). The impact of technostress on role stress and productivity. Journal of Management Information Systems, 24(1), 301-328. https://doi.org/10.2307/40398890

Tarafdar, M., Tu, Q., Ragu-Nathan, T. S., \& Ragu-Nathan, B. S. (2011). Crossing to the dark side: Examining creators, outcomes, and inhibitors of technostress. Communications of the ACM, 54(9), 113-120. https://doi.org/10.1145/1995376.1995403

The Guardian. (2017). Our minds can be hijacked: The tech insiders who fear a smartphone dystopia. Retrieved 3rd November 2017. https://www.theguardian.com/technology/2017/oct/05/smart phone-addiction-silicon-valley-dystopia

Upadhyaya, P., \& Acharya, V. (2020). Impact of technostress on academic the productivity of university students. Education \& Information Technologies. https://doi.org/10.1007/s10639-020 $-10319-9$

Wang, C., Lee, M., \& Hua, Z. (2014). Understanding and predicting compulsive smartphone use: An extension of reinforcement sensitivity approach. ICIS 2014 Proceedings. https://aisel.aisnet. org/icis2014/proceedings/HumanBehavior/47

Wang, J.-L., Wang, H.-Z., Gaskin, J., \& Wang, L.-H. (2015). The role of stress and motivation in problematic smartphone use among college students. Computers in Human Behavior, 53, 181-188. https://doi.org/10.1016/j.chb.2015.07.005

Whelan, E., Najmul Islam, A. K. M., \& Brooks, S. (2020). Is boredom proneness related to social media overload and fatigue? A stressstrain-outcome approach. Internet Research, 30(3), 869-887. https://doi.org/10.1108/INTR-03-2019-0112

Xiao, L., \& Mou, J. (2019). Social media fatigue: Technological antecedents and the moderating roles of personality traits: The case of WeChat. Computers in Human Behavior, 101, 297-310. https://doi.org/10.1016/j.chb.2019.08.001

Zhang, X. (2021). Preparing first-year college students' academic transition: What is the value of complementary web-based learning? Computers \& Education, 172, 104265. https://doi.org/ 10.1016/j.compedu.2021.104265

Zhao, G., Wang, Q., Wu, L., \& Dong, Y. (2021). Exploring the structural relationship between university support, students' technostress, and burnout in technology-enhanced learning. The Asia-Pacific Education Researcher, 10, 1-11. https://doi. org/10.1007/s40299-021-00588-4

Publisher's Note Springer Nature remains neutral with regard to jurisdictional claims in published maps and institutional affiliations. 